\title{
Child Care Providers' Perceptions of Children's Lifestyles and Risk Factors for Obesity: A Focus Group Study
}

\author{
Chiyori Haga ${ }^{1}$, Shizuyo Takagi' ${ }^{2}$, Satoko Nakagomi ${ }^{2}$ \\ ${ }^{1}$ Graduate School of Health Sciences, The University of Okayama, Okayama, Japan \\ ${ }^{2}$ Department of Health Sciences, Interdisciplinary Graduate School of Medicine and Engineering, The University \\ of Yamanashi, Chuo-City, Japan \\ Email: Chiyori@okayama-u.ac.jp
}

Received 4 February 2014; revised 8 March 2014; accepted 16 March 2014

Copyright (C) 2014 by authors and Scientific Research Publishing Inc.

This work is licensed under the Creative Commons Attribution International License (CC BY).

http://creativecommons.org/licenses/by/4.0/

(c) (i) Open Access

\begin{abstract}
Objective: This study attempts to understand child care providers' perceptions of remarkable children's lifestyles and discusses potentially successful strategies of cooperation among child care providers, parents, and health professionals for health promotion and the prevention of obesity in preschool children. Methods: We conducted 6 focus group discussions consisting of 34 child care providers employed by private and public child care centers, and a public kindergarten in Yamanashi Prefecture, Japan. Systematic thematic analysis was conducted to generate themes to address the study questions. Results: What the focus group participants discussed with felt mainly into the 3 different kinds of points: "Concerns of Child Care Providers Regarding Parental Attitudes about Nutrition and Nurture," "Tensions between Parents and Child Care Providers," and "Current Obesity Prevention Activities and the Role of Child Care Professionals." Conclusions: Childcare providers had many concerns that fell into 5 main issues of the possible detrimental effects on children's health due to parents' nurturing methods and lifestyles. Participants described possible strategies for the prevention of childhood obesity in childcare settings as well as barriers to effective intervention. Childcare providers felt that a system to demand helps from public health nurses in guiding parents would be effective in preventing childhood obesity.
\end{abstract}

\section{Keywords}

Preschool Children; Lifestyle; Obesity; Risk Factors; Prevention

\section{Introduction}

In 2010, the World Health Organization (WHO) estimated that about 42 million children worldwide under the 
age of five were overweight and declared that the prevention of childhood obesity was a high priority [1]. In Japan, childhood obesity has been increasing for many years, although recent increases are less steep than those noted earlier [2]. This is a trend similar to that seen in Western countries [3]-[5]. However, the prevention of childhood obesity remains a priority because obesity is associated with cardiovascular [6] [7], endocrine [8] [9], and respiratory diseases [10] among children. Furthermore, high body mass in infancy or early childhood is likely to persist into adulthood [11]-[13]. Since obesity often develops during early childhood, this is also the best time for prevention [14] [15]. Many young children spend much of their time away from home in child care centers, but no methodology has yet been established in Japan, regarding the role of child care centers in obesity prevention [16].

We previously surveyed the situation regarding the prevention of childhood obesity in Yamanashi Prefecture [17] [18], which has had a higher prevalence of childhood obesity than any other area in Japan since 2008 [19]. However, our study found that only half of the public health nurses in healthcare centers in Yamanashi had advised parents to seek medical advice specifically about the prevention of childhood obesity [16]. Moreover, the nurses who acknowledged the importance of preventing obesity often felt that parents were not willing to or capable of nurturing their children in the development of good dietary habits. Our study showed that public health nurses gave their health guidance priority and they regard the guidance for preventing childhood obesity as low priority to avoid burdening parents with too heavy task of nurture to maltreat their children [18]. This suggest that public health nurses may think the guidance for preventing childhood obesity will be a special one to increase parents' the burden of childcare. However, the example of lifestyles relating with childhood obesity are insufficient sleep and chewing, skipping breakfast, and so on [20] [21]. These lifestyles are remarkable problems to need changes. These situations imply that public health nurses may misunderstand the risk of childhood obesity.

The lifestyles of insufficient sleep and skipping breakfast have been pointed out as the problems on childhood lifestyle since 2008 [22]. If the nurses have not had health guidance for parents in spite of knowing these associations, they would not grasp the recent situation on childhood lifestyles. This suggest that the nurses who will have a health guidance for childhood should interview not only parents, but also childcare providers.

Therefore, we clarified child care providers' perceptions of children's lifestyles and the risk factors for obesity, and then examined potentially successful strategies of cooperation. Moreover, the nurses acknowledged the necessity of cooperating with child care providers, but had no guidelines for how to achieve this [18]. The published methods of disease prevention and health promotion for preschool children have not specifically addressed the role of child care providers and public health nurses in the prevention of childhood obesity [23]-[26].

Therefore, the aim of this study was to understand child care providers' perceptions of children's lifestyles and the risk factors for obesity. In addition, we discussed potentially successful strategies of cooperation among child care providers, parents, and health professionals for health promotion and prevention of obesity in preschool children.

\section{Methods}

\subsection{Participants}

We conducted 6 focus group discussions in the spring of 2012, and recruited licensed child care directors by means of letters and follow-up phone calls to oversight boards in charge of child care centers and kindergartens. Twelve of the 18 invited directors attended our focus groups, along with 22 teachers employed by 1 private and 10 public child care centers, and 1 public kindergarten in 2 rural areas of Yamanashi Prefecture, Japan. These areas are located in the eastern and western part of Yamanashi and still rich in nature. In both cities, they have their population of about 30,000 with infrequent traffic to and from the main city. We proposed that child care directors choose the participants. Directors were included because they were willing to attend the focus groups voluntarily.

Written informed consent was obtained at the beginning of each focus group. This study was approved by the Ethical Review Board of the University of Yamanashi, School of Medicine.

\subsection{Conducting the Focus Groups}

Two professional moderators conducted the groups using a structured discussion guide developed by Vaughn and colleagues [27]. All focus groups lasted 90 minutes and were digitally recorded and transcribed verbatim. 
Each group began with broad open-ended questions followed by queries that are more specific. In this way, matters of significance to the participants emerged naturally, before questions of specific interest to the researchers were addressed. The study domains and samples of questions related to each domain are listed in Table 1. The questions explored the following issues: current problems in prevention of childhood obesity, reactions of parents against obesity prevention measures and ideas for lifestyle improvements, and opinions about forming a network of obesity prevention for preschool children. We also used other questions, such as prompts to encourage respondents to answer, and probing questions to obtain more information.

\subsection{Analysis}

All interviews were transcribed into a Microsoft Word table prior to the case analysis according to the methods described by La Pelle [28]. Specifically, we created a list of predefined themes and grouped the responses intothese themes as we searched the text. Next, through prolonged immersion and several re-readings of the data, we identified subthemes within our predefined topics. We then developed a codebook that defined each theme cat-

\section{Table 1. Home situations that concern child care providers.}

Topics of Concern Representative Themes

"I have witnessed mothers giving their babies food that do not fit the developmental stage of their children. And I think children brought up that way will have an unbalanced diet in the future.”

"The parents say that their children eat only staple foods such as rice, but they eat almost the entire school lunch at nursery school."

"I think that the meals mothers cook nowadays are high-calorie and not traditional Japanese foods, and there are many instant foods that they can easily cook."*

“The children don't eat traditional Japanese foods very much because mothers prefer to cook what is easy rather than provide a balanced meal."**

Dietary Habits

"I think mothers provide the foods that their children want to eat rather than the foods we would like to have the children eat."***

"Mothers would give their children foods in adult quantities rather than in quantities appropriate for children.",**

"Many children eat meals without chewing enough. Children prefer tender food.”*

“I think that many mothers don’t encourage their children to chew their food enough, and they don't limit eating to mealtimes.”

“I think that parents don’t pay attention to their children during the meal.”

"Mothers tend to minimize cooking by eating out and buying foods at the convenience store."

Maternal Cooking Ability "Mothers tend to depend on nursery school lunches and prefer to simplify cooking at home.”

"Even if we provide recommended menus, mothers may not be able to cook the recommended meals because they lack basic cooking skills.”

“Children usually eat meals alone at home. This is a recent phenomenon, called 'Koshoku’ in Japan, isn’t it?”

Mealtime Communication

"I think that parents don’t encourage their children to stay at the table because they prefer not to communicate with their children."

"I have found that many children don’t eat breakfast,"

Life Pattern and Life Rhythm

"I think that mothers want to simplify cooking meals because they have full-time jobs.”

"I have found that many children go to sleep late at night and wake up late in the morning."

"I have found that many children are constipated due to the disorder of their daily lives."

“I think that modern parents don't want to let children play outside because they are concerned about the security of their children.”

Playtime Activities

"I think children nowadays prefer to watch TV and play video games indoors rather than play outside.”

“I think that children don’t play with a big group of friends.”

\footnotetext{
${ }^{*}$ The situation can be risk factor directly ${ }^{* *}$ The situation can be risk factor indirectly.
} 
egory, assigned a numerical code for each theme, and provided detailed instructions on coding text by theme code. Finally, we performed coding, sorted text by theme code, and performed code validation.

Data segments related to each theme were entered into tables. Transcripts were then reviewed against the tables by two other investigators to check for thematic material that might have been missed. Further data reduction resulted in a single table of themes. summarise issues that related to participants'

Data analysis was supervised by investigators with extensive qualitative research experience. To confirm the reliability and validity of the results, we examined whether the data segments related to each theme had been overlooked or overlapped, and had external investigators determine if the themes that we created adequately reflected the content of the remarks made by the participants.

\section{Results}

\subsection{Participant Characteristics}

Child care providers ranged in age from 22 to 62 years (mean, 38.6 years) and the years of experience of child care providers ranged from 1 to 38 years (mean, 15.6 years). Among the 34 focus group participants, 21 had the additional experience of having raised their own children.

\subsection{Concerns of Child Care Providers Regarding Parental Attitudes about Nutrition and Nurture}

We found that child care providers' main concerns about their children's home situation revolved around 5 themes such as follows: "Dietary Habits," "Maternal Cooking Ability," "Mealtime Communication," "Life Pattern and Life Rhythm," and "Playtime Activities" (Table 1). These included the situations that children usually eat high-calorie foods and meals without chewing enough, do not eat breakfast, and sleep late at night and wake up late in the morning.

"Dietary Habits" contained topics such as how the providers were able to ascertain the children's dietary habits through the contents of the baby food left for the children and through the results of the dietary survey conducted by each center annually to determine whether parents were providing food appropriate to the developmental level of their children. It was also common for the providers to hear parents talk about meals or ingredients that their children would not eat, even though the children ate the same or similar foods in the care center. The providers also commented that the children's posture at the dining table and incorrect use of tableware suggested that the children had not been properly trained in table manners at home. They attributed these observations to lax parental attitudes toward proper nourishment and acquisition of desirable dietary habits by their children. This theme included the situation that children usually eat high-calorie foods and meals without chewing enough, and eat unbalanced meal.

The themes "Maternal Cooking Ability" and "Mealtime Communication" contained issues such as how parents avoided cooking by eating out or by buying convenience store meals, and how they depended on the lunches at the child care center to supplement their children's nutrition. The providers added that the children often ate their meals alone at home. Furthermore, they felt that parents, especially fathers and younger mothers, could not cook meals without the use of recipes. They also observed that the children did not show much interest in food and attributed this to a lack of communication about ingredients and cooking methods. They felt that such discussions during meal times at home could make the meals more attractive to the children. This theme included the situation that children tend to eat out and foods selled at the convenience store and they do not stay at the table during meal time.

In the theme "Life Pattern and Life Rhythm," the providers felt that parents did not devote enough time to their children in the morning because they were in a hurry to get to the office and commented that parents seemed to live their lives for themselves without thinking about the needs of their children. In fact, some providers had witnessed situations in which young children ate their dinner in bars, or were taken by their parents to venues for adult entertainment, such as pachinko parlors (similar to a Western slot machine arcade). Examples such as these raised concerns that parents place more importance on their own leisure than on cultivating stable circadian rhythms in their children because bringing their children along for these activities might lead to their children having night-oriented lifestyles with irregular mealtimes and bedtimes. This theme included the situation that children do not eat breakfast and sleep late at night and wake up late in the morning. 
Concerns such as increased incidence of illnesses due to decreased physical activity and obesity in children were raised in the theme "Playtime Activities." However, the providers also understood that this might be due to parents wanting to keep their children safe. As a result, this theme included the situation that children do not play outside and prefer to watch TV and play video games indoor rather than play outside.

\subsection{Tensions between Parents and Child Care Providers}

We found that providers had conflicts with parents over how parents should care for their children at home and the sort of care that parents expect of the providers at child care centers. The providers felt that the responsibility of imparting knowledge, such as basic table manners and healthy bowel habits, to the children had been shifted to them from the parents. They also felt that parents depended on them too much for their children's discipline and cleanliness, and opined that parents found these matters too troublesome. At the same time, the providers complained that parents often did not accept their instructions regarding child care.

\subsection{Current Obesity Prevention Activities and the Role of Child Care Professionals}

The providers were unsure about how and when they should intervene to help prevent obesity during the early childhood years and many expressed little concern about mild to moderate obesity. Many of them also hesitated to intervene even if they wanted to help because they were afraid that parents might restrict their children's meals in response to the word "obesity." In addition, many providers felt that parents viewed them only as "baby sitters," although some viewed themselves as substitute parents, taking significant responsibility for the health of the children they served.

\subsection{Potentially Successful Strategies for Prevention of Childhood Obesity in Child Care Settings}

Child care providers described several potentially feasible and effective strategies for the prevention of childhood obesity in child care settings as well as potential barriers (Table 2). They suggested several strategies, such as informing parents about the standard amount of meals for children and age-specific body sizes, distributing pamphlets about the reasons for prevention of childhood obesity, and growing vegetables in child care centers so that children would be interested in their meals. They also mentioned that developing free Internet sites that allow parents to assess their children's body sizes is one of the most effective strategies to provide health education to parents about the prevention of obesity.

Most child care providers expressed a desire to learn more about health promotion because they felt that their lack of knowledge could be detrimental to the children they cared for. Some providers noted that cooperation

Table 2. Barriers to and potential successful strategies for prevention of childhood obesity.

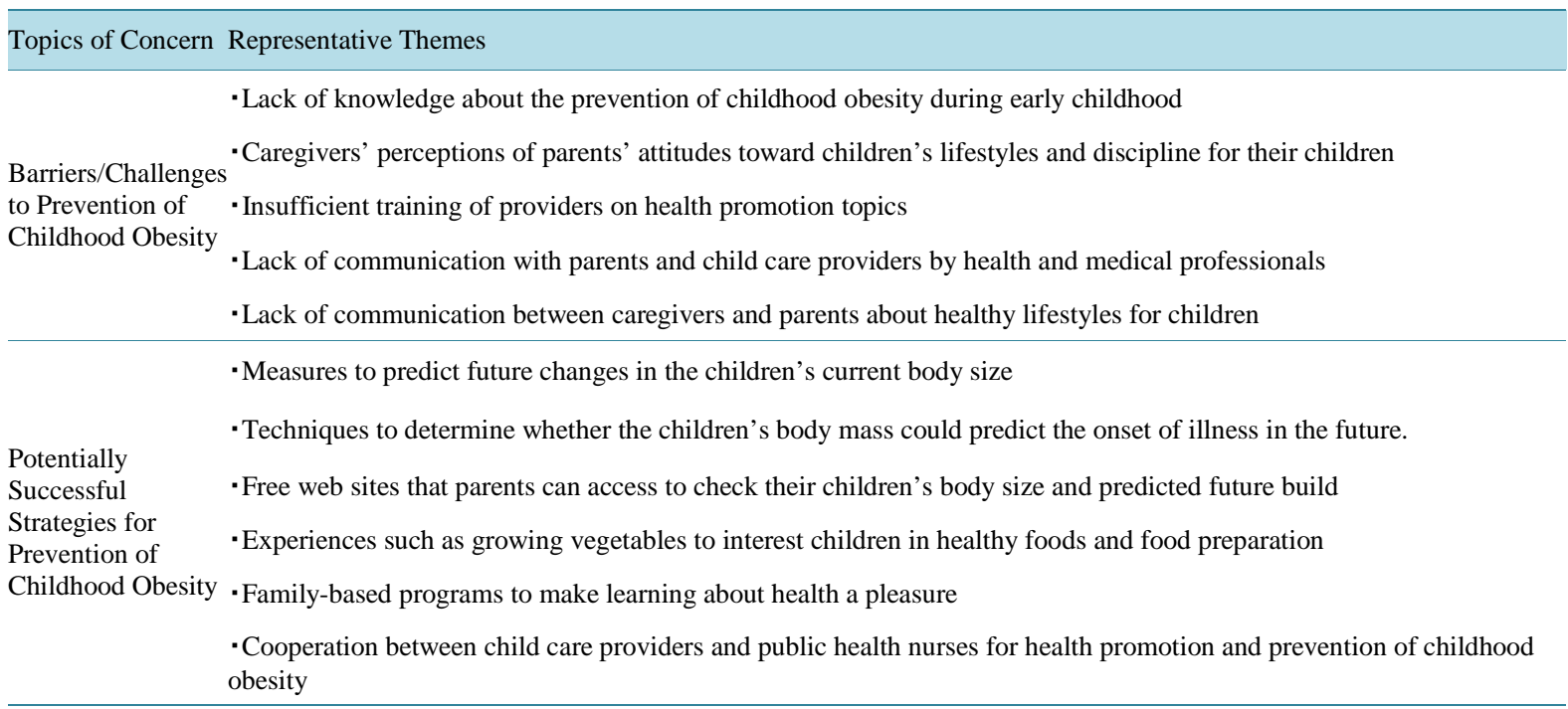


between health professionals (e.g. nutritionists, food supply workers at the centers, and public health nurses) and child care providers was insufficient. For example, the providers wanted better communication with public health nurses to instruct parents on the care of and on disciplining their children at home. All agreed that they needed to play a part in lifestyle-related and family-based disease prevention, although some felt that this role would be more appropriate for public health nurses.

\section{Discussion}

Many studies from western countries suggest the strategies for prevention of preschool-age children's obesity, while a few is known in Asia. In this qualitative study, we obtained views directly from child care providers in a rural Japanese area regarding the perceived the recent children's lifestyles including related factors of childhood obesity in child care settings. We also obtained their views about which strategies they felt would be most effective in these settings. Child care providers expressed a need to cooperate with health professionals, such as nutritionists, food supply workers at the centers, and public health nurses to prevent childhood obesity and promote good health. They also expressed a need for sufficient knowledge about the best times and methods for communicating with families about the prevention of childhood obesity. Often, child care providers do not see childhood obesity or being overweight as a threat to children's future health because plump children are considered healthy and vigorous [26]. In addition, many parents are usually more concerned with how their children are developing socially and whether they are making friends [25]. These suggest that the providers and parents may not tend to regard childhood obesity and overweight as a serious problem and have not treated them for preventing obesity. These may be reasons why no methodology has been established in Japan.

Fortunately, obesity in early childhood is not a severe problem in Japan yet. A recent survey of 286 infants in child care settings who were randomly selected in the Kinki district showed that the prevalence of childhood obesity (defined as more than $20 \%$ over the normal weight) was only $1.8 \%$ [29]. However, it is normal for children's body mass index (BMI, body weight $[\mathrm{kg}] /$ height $[\mathrm{m}]^{2}$ ) to decrease from infancy to age $5-6$. For most children, adiposity also decreases around the age of 6 years [30]. This phenomenon is called "adiposity rebound" (AR). Children who experience AR before the age of 6 are more likely to become obese. A previous study found that children who experienced AR around age 3 were obese throughout childhood [31]. These observations suggest that children with a standard body mass will be slim at age 5 or 6 and that children who may be at risk for obesity will likely be slim at age 3 . Since child care providers typically care for children during early childhood, they seldom encounter obese children. However, they may encounter children who have already experienced AR before age 6 and who are therefore at a greater risk for future obesity. Moreover, it is known that body mass in infancy or early childhood is likely to remain more constant in adulthood adulthood [11]. In fact, our results implied that the providers were aware of the magnitude of problems regarding preschool children's obesity and the importance of its prevention. However, our results also showed that the providers complained that parents often did not accept their instructions regarding child care because parents viewed them only as "baby sitters." This suggests that health professionals should teach the parents how to care their children for prevention of obesity when the providers help the help professionals their instruction for parents. But there is insufficient evidence enough to prevent the obesity of preschool children. Future studies are needed to determine the onset times of obesity in children in order to establish the best timing for interventions to prevent childhood obesity.

Our focus group study showed that child care providers were concerned about the dietary habits (e.g., skipping breakfast, insufficient chewing) and circadian rhythms (e.g., insufficient sleep, night-oriented lifestyle). These lifestyles might put the children at risk for obesity [20]. However, our results showed that providers were afraid that parents might restrict their children's meals in response to the word "obesity." Parents and perhaps providers also, might not recognize the associations between these factors and obesity because they may regard limiting food intake, be it meal size or frequency, as the best way to prevent obesity. It is, thus, important for child care providers and parents to be aware that the point is not to restrict their children's food intake, but rather to focus on the ideal lifestyle - for example, eating breakfast every day —in the formulation of intervention programs to prevent obesity.

In addition, our study has uncovered the tensions between parents and child care providers. The providers highlighted parental inadequacies in feeding their children to promote healthy growth and training them to have attitudes required for a healthy lifestyle. They also considered it especially important that parents not allow their children to refuse foods that do not appeal to them. Some of the factors that they thought were most likely to contribute to unbalanced dietary habits included the following: using store-bought baby food, skipping breakfast, 
and parents' lack of cooking experience [32], and lack of caring to stay at the table during meal time [33]. This is a valid concern because an unbalanced diet provides children with less or excessive amounts of necessary nutrients, which may lead to obesity depending on the dietary contents [34]. These suggested that the parental resolution to nurture their children healthily is needed. Sleeping late at night and preferring to watch TV and play video games indoor rather than play outside may lead to obesity, too [35].

This study indicated that the providers felt that parents needed to take the importance of a healthy lifestyle and the discipline of their children more seriously. However, it may be difficult to make parents take the best care of their children. In fact, the providers felt the tension between parents and themselves when they tried to advice about child care. Although every parent would want their children to grow healthily, they did not accept the advice for child health. This implies that the direction of parents' effort might be wrong. Thus, at the first step, health professionals share of the information about the problems with present life styles to cooperate among them. Second, they set out their objectives to solve the problems together through the trust between parents and health professionals. The professionals might be a public health nurse because they can form a close relationship with parents since they had cared the parents (especially mothers) since the mothers conceived.

In addition to relational problems, a night-oriented lifestyle can be a risk factor for obesity due to insufficient sleep, late bedtime [36], and late-night snacking [37]. Many of the issues that concerned child care providers about the nurture children receive at home are issues related to the prevention of obesity, but the providers often felt uncomfortable offering guidance because of the fear of being treated with contempt by the parents. However, one previous study in 2007 that surveyed approximately 900 parents of young children about health education for the prevention of obesity showed that almost $90 \%$ of the parents wanted to know how to prevent childhood obesity and related lifestyle diseases [38]. We consider that many health professionals, including public health nurses, tend to regard obesity and lifestyle diseases as serious for children. In fact, there are few papers regarding the prevention of these diseases during childhood in Japan [17]. Thus, a system is needed that allows providers to seek help from health professionals in guiding interested parents.

There are no clear strategies for the prevention of childhood obesity, although many studies (mainly in Western countries) have been carried out on this issue [39]. The risk factors for lifestyle diseases vary and are interconnected, and no single method will be sufficient for risk reduction. Modern children grow up in an environment of excessive calorie intake and limited energy expenditure. Therefore, it is important that public health authorities promote the healthy environment for children to eat a healthy food and play actively. The evidence to make a policy is needed. A recent systematic review article demonstrated the need for more research and consistent methods to understand the comparative effectiveness of childhood obesity prevention programs in community settings [40]. The research should address when and how to prevent obesity. Therefore, we should plan to conduct studies that can provide strong evidence, for example, randomized control trials or longitudinal cohort studies. We should use the public health service (e.g., health checkups during infancy, the various programs for "Food and Nutrition Education," etc.) and establish a system that enables health professionals and researchers to use data from every child at any time through the involvement of local government. Cooperation is needed among child care providers and nurses in child care centers who care for the children over a long period, between public health nurses and pediatric doctors who can check the health of the children, and nutritionists who can assess the children's food intake. For example, the sorts of cooperation are as follows, the children's health data of the monthly and annual checkup in child care centers can be inspected by nurses including public health nurses. When the nurses who find the explicit or potential health problems, they could take a conference for prevent or solving the problems. However, additional effective strategies are needed, as well as increased cooperation among child care providers and health professionals, such as public health nurses, nutritionists, and pediatricians, as well as local government.

One potential limitation of the present study is the lack of generalizability, since the sample consisted of participants from only one region in Japan. However, as the themes we report here recurred often in the focus groups, we considered the data to be saturated. Another limitation is that our results might be biased by the question that demanded a solution from public health nurses for the participants' needs. However, we could not avoid this problem since we had to look at the main theme in such a limited time.

\section{Conclusion}

Childcare providers had many concerns that fell into 5 main issues, which were "Dietary Habits," " Maternal Cooking Ability,” “ Mealtime Communication,” “ Life Pattern and Life Rhythm,” and “ Playtime Activities,” of 
the possible detrimental effects on children's health due to parents' nurturing methods and lifestyles. Differences of opinion between providers and parents created tensions, with providers not knowing when or how to intervene when they had concerns. Participants described possible strategies for the prevention of childhood obesity in child care settings as well as barriers to effective intervention. Childcare providers felt that a system in which they could seek help from public health nurses in guiding parents in child care would be effective in preventing childhood obesity. They also expressed a desire to increase their own knowledge about health promotion in order to increase their ability to help the children in their care.

\section{Acknowledgements}

The authors are grateful to all the participants of this study. This work was supported by a Grant-in-Aid for Scientific Research (KAKENHI 21792301, 24792544) from the Ministry of Education, Culture, Sports, Science and Technology, Japan.

\section{References}

[1] World Health Organization (2012) Childhood Overweight and Obesity. Global Strategy on Diet, Physical Activity and Health. http://www.who.int/dietphysicalactivity/childhood/en/

[2] Ministry of Education, Culture, Sports, Science, and Technology, Japan (2010) School Hygiene Statistics Working Papers. http://www.mext.go.jp/b_menu/toukei/chousa05/hoken/kekka/1268813.htm

[3] Lissner, L., Sohlström, A., Sundblom, E. and Sjöberg, A. (2010) Trends in Overweight and Obesity in Swedish Schoolchildren 1999-2005: Has the Epidemic Reached a Plateau? Obesity Reviews, 11, 553-559. http://dx.doi.org/10.1111/j.1467-789X.2009.00696.x

[4] Ogden, C.L., Carroll, M.D., Kit, B.K. and Flegal, K.M. (2012) Prevalence of Obesity and Trends in Body Mass Index among US Children and Adolescents, 1999-2010. JAMA: The Journal of the American Medical Association, 307, 483-490. http://dx.doi.org/10.1001/jama.2012.40

[5] Olds, T.S., Tomkinson, G.R., Ferrar, K.E. and Maher, C.A. (2009) Trends in the Prevalence of Childhood Overweight and Obesity in Australia between 1985 and 2008. International Journal of Obesity, 34, 57-66. http://dx.doi.org/10.1038/ijo.2009.211

[6] Freedman, D.S., Dietz, W.H., Srinivasan, S.R. and Berenson, G.S. (1999) The Relation of Overweight to Cardiovascular Risk Factors among Children and Adolescents: The Bogalusa Heart Study. Pediatrics, 103, 1175-1182. http://dx.doi.org/10.1542/peds.103.6.1175

[7] Weiss, R., Dziura, J., Burgert, T.S., Tamborlane, W.V., Taksali, S.E., Yeckel, C.W. and Caprio, S. (2004) Obesity and the Metabolic Syndrome in Children and Adolescents. The New England Journal of Medicine, 350, 2362-2374. http://dx.doi.org/10.1056/NEJMoa031049

[8] Lewy, V.D., Danadian, K., Witchel, S.F. and Arslanian, S. (2001) Early Metabolic Abnormalities in Adolescent Girls with Polycystic Ovarian Syndrome. Journal of Pediatrics, 138, 38-44. http://dx.doi.org/10.1067/mpd.2001.109603

[9] Ludwig, D.S. and Ebbeling, C.B. (2001) Type 2 Diabetes Mellitus in Children: Primary Care and Public Health Considerations. JAMA: The Journal of the American Medical Association, 286, 1427-1430. http://dx.doi.org/10.1001/jama.286.12.1427

[10] Figueroa-Munoz, J.I., Chinn, S. and Rona, R.J. (2001) Association between Obesity and Asthma in 4 - 11 Year Old Children in the UK. Thorax, 56, 133-137. http://dx.doi.org/10.1136/thorax.56.2.133

[11] Bao, W., Srinivasan, S.R., Wattigney, W.A. and Berenson, G.S. (1994) Persistence of Multiple Cardiovascular Risk Clustering Related to Syndrome X from Childhood to Young Adulthood. The Bogalusa Heart Study. Archives of Internal Medicine, 154, 1842-1847. http://dx.doi.org/10.1001/archinte.1994.00420160079011

[12] Morrison, J.A., Friedman, L.A., Wang, P. and Glueck, C.J. (2008) Metabolic Syndrome in Childhood Predicts Adult Metabolic Syndrome and Type 2 Diabetes Mellitus 25 to 30 Years Later. Journal of Pediatrics, 152, 201-206. http://dx.doi.org/10.1016/j.jpeds.2007.09.010

[13] Tsukada, H., Miura, K., Kido, T., Saeki, K., Kawashima, H., Ikawa, A., Nishi, M., Morikawa, Y., Nishijo, M., Nakanishi, Y., Yoshita, K. and Nakagnawa, H. (2003) Relationship of Childhood Obesity to Adult Obesity: A 20-Year Longitudinal Study from Birth in Ishikawa Prefecture, Japan. Nihon Koshu Eisei Zasshi, 50, 1125-1134.

[14] Yamamoto, M. and Kuzuhara, M. (2004) When Does Childhood Obesity Develop? ChiikiIryo, 42, 74-78.

[15] Nakashima M. (2002) Discussion of Percent of Body Fat, Serum Lipid, Life Style in Childhood Obesity. Shimane Medical Association, 22, 225-229.

[16] Haga, C., Aihara, M., Yamagata, Z. and Yamazaki, Y. (2012) Measures to Prevent Childhood Obesity by Community 
Health Nurses in Municipality in Yamanashi Prefecture. Hokenshi Journal, 68, 990-996.

[17] Haga, C., Aihara, M. and Yamazaki, Y. (2011) A Study of Literature to Clarify the Status and Future Research Tasks of Obesity Prevention among Preschool Children in Japan. Japan Academy of Community Health Nursing, 13, 119124.

[18] Haga, C., Sakurai, M., Aihara, M. and Yamazaki, Y. (2012) Public Health Nurses’ Cognition and Attitudes towards the Prevention of Childhood Overweight and Obesity. Yamanashi Nursing Journal, 10, 1-6.

[19] Yamanashi Planning Survey and Statistics Office (2010) Education Statistics Investigation Reports in Yamanashi Prefecture 2008. http://www.pref.yamanashi.jp/toukei_2/HP/DATA/22kyouikutoukei.pdf

[20] Sato, N and Yoshiike, N. (2010) Factors Associated with the Masticatory Behavior of Children Assessed by the Number of Chews for a Test Meal of Usual School Lunch Menu. Japanese Journal of Nutrition Dietetics, 68, $253-262$. http://dx.doi.org/10.5264/eiyogakuzashi.68.253

[21] Kodama, H. (2011) Current Status and Treatment of Obesity and Lifestyle-Related Diseases in Children. Teikyo Medical Journal, 34, 219-226.

[22] Matsuo, Y., Kodama, H., Ohno, R., Saruta, T., Atomi, H., Endoh, G. and Tabata, I. (2008) Lifestyle Disease Prevention since Pre- and Postnatal.

http://www.scj.go.jp/ja/info/kohyo/pdf/kohyo-20-t62-4.pdf\#search=\%E6\%88\%91\%E3\%81\%8C\%E5\%9B\%BD+\%E5 \%AD\%90\%E3\%81\%A9\%E3\%82\%82+\%E7\%94\%9F\%E6\%B4\%BB+\%E5\%95\%8F\%E9\%A1\%8C

[23] Freedman, M.R. and Alvarez, K.P. (2010) Early Childhood Feeding: Assessing Knowledge, Attitude, and Practices of Multi-Ethnic Child-Care Providers. Journal of the American Dietetic Association, 110, 447-451. http://dx.doi.org/10.1016/j.jada.2009.11.018

[24] Taveras, E.M., LaPelle, N., Gupta, R.S. and Finkelstein, J.A. (2006) Planning for Health Promotion in Low-Income Preschool Child Care Settings: Focus Groups of Parents and Child Care Providers. Ambulatory Pediatrics, 6, 342-346. http://dx.doi.org/10.1016/j.ambp.2006.07.004

[25] Kuboyama, S., Saito, Y., Nishimaki, K., Toushima, S., Fujii, S. and Takigawa, K. (2009) Survey on Awareness of and Response to "Children of Concern" and "Parents of Concern" by Preschool Teachers and Child-Care Providers: Considerations in Providing Organizational Support to Preschools and Child-Care Centers. Bulletin of the National Institute of Special Needs Education, 36, 55-76.

[26] Kiuchi, T., Wang, L., Okada, A., Jono, H. and Ono, A. (2007) Research on Nursery Nurses’ Perception about Children’s Health and Practice for Health Management for Children. Gunma Paz College Journal, 2, 641-651.

[27] Vaughn, S., Schumm, J.S. and Sinagub, J.M. (1999) Focus Group Interviews in Education and Psychology. Sage Publications, Inc., Thousand Oaks.

[28] La Pelle, N. (2004) Simplifying Qualitative Data Analysis Using General Purpose Software Tools. Field Methods, 16, 85-108. http://dx.doi.org/10.1177/1525822X03259227

[29] Kibayashi, E., Ueno, Y. and Nishitani, K. (2009) Comparative Studies on Dietary Habits of Preschool Children in Infant School and Nursery School. Sonoda Journal, 43, 85-101.

[30] Rolland-Cachera, M.F., Deheeger, M., Bellisle, F., Semp, M., Guilloud-Bataille, M. and Patois, E. (1984) Adiposity Rebound in Children: A Simple Indicator for Predicting Obesity. American Journal of Clinical Nutrition, 39, 129-135.

[31] Dietz, W.H. (2000) “Adiposity Rebound”: Reality or Epiphenomenon? Lancet, 356, 2027-2028. http://dx.doi.org/10.1016/S0140-6736(00)03396-1

[32] Shiraki, M., Omura, M. and Marui, E. (2008) Relationship between Unbalanced Diet and Living Environment in Infancy. Japanese Journal of Health \& Human Ecology, 74, 279-289. http://dx.doi.org/10.3861/jshhe.74.279

[33] Hayashibe, H., Uchida, N., Kodera, H., Dobashi, K., Asayama, K. and Nakazawa, S. (2003) The Care for Childhood Obesity at Pediatric Outpatient Clinic. Japanese Journal of Pediatrics, 56, 2475-2481.

[34] Parízková, J. and Hills, A.P. (2005) Childhood Obesity: Prevention and Treatment. 2nd Edition, CRC Press, Boca Raton.

[35] Mizutani, T., Suzuki, K., Kondo, N. and Yamagata, Z. (2007) Association of Maternal Lifestyles Including Smoking during Pregnancy with Childhood Obesity. Obesity, 15, 3133-3139. http://dx.doi.org/10.1038/oby.2007.373

[36] Al Mamun, A., Lawlor, D.A., Cramb, S., O’Callaghan, M., Williams, G. and Najman, J. (2007) Do Childhood Sleeping Problems Predict Obesity in Young Adulthood? Evidence from a Prospective Birth Cohort Study. American Journal of Epidemiology, 166, 1368-1373. http://dx.doi.org/10.1093/aje/kwm224

[37] Arble, D.M., Bass, J., Laposky, A.D., Vitaterna, M.H. and Turek, F.W. (2009) Circadian Timing of Food Intake Contributes to Weight Gain. Obesity, 17, 2100-2102. http://dx.doi.org/10.1038/oby.2009.264

[38] Man, M., Kinami, C. and Mikuni, M. (2011) Needs of Preschoolers’ Parents about Health Education for Preventing 
Obesity. Journal of School of Nursing and Social Services, Health Sciences University of Hokkaido, 7, 37-44.

[39] Han, J.C., Lawlor, D.A. and Kimm, S.Y. (2010) Childhood Obesity. Lancet, 375, 1737-1748. http://dx.doi.org/10.1016/S0140-6736(10)60171-7

[40] Bleich, S.N., Segal, J., Wu, Y., Wilson, R. and Wang, Y. (2013) Systematic Review of Community-Based Childhood Obesity Prevention Studies. Pediatrics, 132, e201-e210. http://dx.doi.org/10.1542/peds.2013-0886 